\title{
(DES)MILITARIZACIÓN Y VIOLENCIA POLÍTICA: DESAPARICIÓN FORZADA EN EL NORTE DE MÉXICO
}

\section{RESUMEN}

1 l texto tiene por objetivo central, presentar una discusión en torno a las implicaciones que la estrategia de militarización de la seguridad pública en los últimos 15 años ha generado en relación al incremento de la violencia en varios sectores de la población y, de manera específica, a la práctica de la desaparición forzada por parte agentes del Estado mexicano en la región fronteriza del estado de Chihuahua. A partir del análisis de diversas fuentes, devela cómo la puesta en marcha del Operativo Conjunto Chihuahua-Juárez, constituyó la muestra de una política basada en la producción de cuerpos eliminables.

Palabras clave: militarización, violencia política, necropoder, desaparición forzada, Ciudad Juárez.

1 Profesor-investigador de la Universidad Autónoma de Ciudad Juárez. 


\begin{abstract}
The text presents a discussion about the implications that the strategy the militarization of public security in the last 15 years, has generated about the increase in violence in various sectors of the population, and specifically in practice of the forced disappearance by agents of the Mexican State in the border region of the state of Chihuahua. From the analysis of sources, it reveals how the implementation of the Operativo Conjunto Chihuahua-Juarez, was the example of a policy based on the production of disposable bodies.
\end{abstract}

Key words: militarization, political violence, necropower, forced disappearance, Ciudad Juarez.

\title{
INTRODUCCIÓN
}

El texto sostiene que la desaparición forzada, ha constituido un mecanismo por parte del Estado mexicano que remite a la lógica de necropolítica (Mbembe, 2011), perspectiva que según el filósofo camerunés da cuenta cómo gobiernos someten la vida a un poder encargado de reproducir la muerte como dispositivo de control. En este sentido, la relación entre militarización y violencia política, adquiere relevancia en un contexto sociohistórico en la frontera norte de México, caracterizado por una expansión del brazo punitivo del estado, la extinción de las políticas de bienestar, y la puesta en marcha de una estrategia selectiva encargada de contener y desaparecer vidas consideradas eliminables (Salazar y Curiel, 2012). Reconociendo un esfuerzo por legislar en la materia, resultado de la presión de diversos organismos de derechos humanos y sectores de la sociedad civil, en noviembre del 2017 se publicó en el Diario Oficial de la Federación, la Ley en Materia de Desaparición Forzada de Personas, Desaparición cometida por Particulares, y del Sistema Nacional de Búsqueda de Personas. En ella, un aspecto relevante es la referencia no solo a agentes del Estado vinculados a la desaparición forzada, sino también a la figura 
de "particulares". ${ }^{2}$ En las dos últimas décadas, no podemos obviar que un actor central en la generación de violencias en diversas regiones del país, y en particular en la desaparición de personas en la región fronteriza del norte, ha sido el crimen organizado y el narcotráfico (Quintana, 2013). Reconociendo la complejidad que significa la participación de diversos actores en este tipo de práctica, ${ }^{3}$ concentraré el texto en la desaparición forzada realizada por agentes del Estado mexicano, y en particular a la ejercida por integrantes de las fuerzas armadas en el contexto de implementación del Operativo Conjunto Chihuahua-Juárez, refiriendo en particular al Caso Alvarado Espinoza y Otros vs. México.

El artículo comprende cuatro apartados. El primero describe la relación entre las categorías de violencia política y seguridad pública, la implementación de una política contenciosa y de violación sistemática a derechos humanos, a partir de la puesta en marcha de operativos policiaco-militares subordinados a la operatividad logística castrense. Para ello, describe qué significó el Operativo Conjunto Chihuahua-Juárez, con una presencia entre el 2008 y el 2011, así como el andamiaje que significó el compromiso de implementación de este tipo de política a partir del acuerdo binacional Iniciativa Mérida.

El segundo apartado retoma la categoría de necropoder (Mbebme, 2011), para evidenciar la configuración de una política de militarización de la seguridad pública, dando como resultado la violación sistemática a derechos humanos, y específicamente la práctica de la desaparición forzada por agentes del Estado mexi-

2 En su artículo 27, dicha ley sostiene "Comete el delito de desaparición forzada de personas, el servidor público o el particular que, con la autorización, el apoyo o la aquiescencia de un servidor público, prive de la libertad en cualquier forma a una persona, seguida de la abstención o negativa a reconocer dicha privación de la libertad o a proporcionar la información sobre la misma o su suerte, destino o paradero" (Nueva Ley DOF 17-11-2017; 08)

3 El Centro de Derechos Humanos Miguel Agustín Pro Juárez, A.C., ha sido una figura destacada en el análisis del fenómeno. Al respecto sostiene que, si bien la desaparición por parte de un particular debe ser juzgada a partir de criterios jurídicos específicos, "esto no significa que aunque no intervengan directamente servidores públicos en la detención o privación de la libertad de la víctima, no se puede concluir que no se trata de una desaparición forzada pues el hecho pudo haber sido tolerado o consentido por una autoridad." (Centro PRODH, 2018). 
cano vinculados a los operativos conjuntos. Para fortalecer dicho argumento, el tercer apartado muestra el caso ante la Corte Interamericana de Derechos Humanos (CIDH) sobre desaparición forzada -Caso Alvarado Espinoza y Otros vs. México-, que significó la evidencia pública a partir de una sentencia condenatoria, de cómo las fuerzas armadas han implementado una serie de prácticas violatorias a los derechos humanos, así como la severa crisis de paradigma en torno a la seguridad pública que enfrenta el Estado mexicano. Un aspecto clave resultado de la sentencia emitida por la Corte, fue el establecer cuatro principios básicos de regulación que deben imperar en cualquier intención de favorecer la actuación de las fuerzas armadas en tareas reservadas a la policía civil: extraordinaria, subordinada y complementaria, regulada, y fiscalizada.

El cuarto apartado busca dar un giro de interpretación a lo que ha significado la simulación de cambio en torno a la perspectiva de seguridad pública por parte del actual gobierno federal, encabezado por Andrés Manuel López Obrador. En febrero de 2019, se emitió el decreto por el que se crea el organismo denominado Guardia Nacional. Una organización "híbrida" que plantea operar a partir de una relación dual civil-militar, en tareas de apoyo a la seguridad pública, y que ha generado un fuerte debate en el marco de los derechos humanos.

\section{PAISAJE DE MILITARIZACIÓN DE LA SEGURIDAD PÚBLICA (VIOLENCIA POLÍTICA) EN EL NORTE DE MÉXICO}

Si bien, a lo largo de la historia en México se han mostrado las implicaciones de la participación de elementos de las fuerzas armadas en diversas tareas vinculadas a labores de la policía civil, en las dos últimas décadas ha sido una constante la presencia de operativos policiaco-militares en torno a tareas destinadas a la seguridad pública, en las que la constante es la violación sistemática a derechos humanos reconocidos por el propio Estado mexicano. Por violencia política, haré referencia a todo proceso instrumentalizado y orientado a la formación, distribución y ejerci- 
cio del poder por parte del Estado, para establecer un dominio de facto sobre una región y su población (González, 2017). Partiendo de ello, militarización de la seguridad pública implica la subordinación de las tareas prevención, investigación y persecución de diversos delitos, tanto del fuero común como federal, a la actuación y estrategia represiva castrense que, en el contexto reciente de crisis en relación a la inoperancia del Estado para contener los altos índices de violencia en diversas regiones del país, ha constituido una medida en la búsqueda de legitimar la posición del Estado ante la presencia del narcotráfico y el crimen organizado. El artículo 89 de la Constitución Política de los Estados Unidos Mexicanos, establece las facultades y obligaciones para el Presidente de la República, y en su inciso VI sostiene: "Preservar la seguridad nacional, en los términos de la ley respectiva, y disponer de la totalidad de la Fuerza Armada permanente o sea del Ejército, de la Armada y de la Fuerza Aérea para la seguridad interior y defensa exterior de la Federación." (Constitución Política de los Estados Unidos Mexicanos, 2020). Si bien este aspecto permite al titular del Ejecutivo federal disponer de las fuerzas armadas para tareas de intervención en zonas afectadas por un conflicto o perturbación grave a la paz pública, a continuación sostenemos que dicha atribución fue excedida en el contexto de los últimos años en el estado de Chihuahua, dando como resultado una práctica sistemática de violaciones a derechos humanos. ${ }^{4}$

En esta línea, el artículo 29 de la Constitución, prescribe los escenarios en los que el Presidente de la República, "podrá restringir o suspender en todo el país o en lugar determinado el ejercicio de derechos y garantías que fuesen obstáculo para hacer frente, rápida y fácilmente a la situación” (Constitución Política de los Estados Unidos Mexicanos). Sin embargo, dicha atribución

4 El artículo 29 de la Constitución, prescribe los escenarios en los que el Presidente de la República, "podrá restringir o suspender en todo el país o en lugar determinado el ejercicio de derechos y garantías que fuesen obstáculo para hacer frente, rápida y fácilmente a la situación” (Constitución Política de los Estados Unidos Mexicanos). Sin embargo, esta atribución se encuentra condicionada a la aprobación del Congreso de la Unión, y hasta el 2014 en que se realizó una reforma al artículo, se consideraba el acuerdo con los titulares de las Secretarías de Estado y Procuraduría General de la República. Consultar para mayor referencia Diario Oficial de la Federación 10-02-2014. 
se encuentra condicionada a la aprobación del Congreso de la Unión, y hasta el 2014, en que se realizó una reforma al artículo, se consideraba el acuerdo con los titulares de las Secretarías de Estado y Procuraduría General de la República (DOF 10-02-2014). También debemos considerar que en el año 2007 se incorporó una serie de párrafos, los cuáles establecen los límites obligados en los alcances de suspensión o restricción. Entre los puntos a destacar se menciona que por ningún motivo se podrán suspender derechos como la no discriminación, el reconocimiento a la persona jurídica, a la vida, a la integridad personal, a la protección familiar entre otros; y que toda restricción o suspensión debe estar en proporción al peligro que se enfrenta bajo principios de legalidad, racionalidad, proclamación, publicidad y no discriminación (artículo 29, Constitución Política de los Estados Unidos Mexicanos). Para el caso específico que analizaremos más adelante, dará cuenta que la puesta en marcha de los operativos militares vinculados a tareas de seguridad pública, a partir de 2007, violaron sistemáticamente los preceptos establecidos en dicho artículo.

El primer aspecto a destacar, refiere a lo que varios autores han planteado como la ambigüedad jurídico-procedimental en torno a la perspectiva de la seguridad pública, dando como resultado la tendencia de ampliar el rango de participación de elementos de las fuerzas armadas. Al respecto, el artículo 21 de la Constitución establece por seguridad pública:

“...una función del Estado a cargo de la Federación, las entidades federativas y los Municipios, cuyos fines son salvaguardar la vida, las libertades, la integridad y el patrimonio de las personas, así como contribuir a la generación y preservación del orden público y la paz social, de conformidad con lo previsto en esta Constitución y las leyes en la materia. La seguridad pública comprende la prevención, investigación y persecución de los delitos, así como la sanción de las infracciones administrativas, en los términos de la ley, en las respectivas competencias que esta Constitución señala. La actuación de las instituciones de seguridad pública se regirá por los principios de legalidad, objetividad, eficiencia, profesionalismo, honradez 
y respeto a los derechos humanos reconocidos en esta Constitución" (Constitución Política de los Estados Unidos Mexicanos).

Esta definición, en la perspectiva de Muñoz Castellanos (2017), presenta dos interrogantes centrales. Por un lado, no queda claro en manos de quién se cumple dicho mandato, es decir la autoridad o cuerpo ejecutor de dicha prevención; mientras que por otro lado, coloca dos enfoques enfrentados entre sí, resultando con ello una serie de ambigüedades en la interpretación jurídica: la prevención y la reacción: "si bien es cierto que su corte es preventivo, también es cierto que al señalar las facultades de investigación y persecución ambas representan el corte reactivo de la seguridad pública” (Muñoz, 2017: 150).

Más allá de una discusión a fondo, con respecto a la falta de claridad conceptual que enfrenta el enfoque de la seguridad pública en su anclaje normativo y procedimental, es importante dar cuenta de las implicaciones que ha generado la participación de elementos de las fuerzas armadas en torno a la dicha ambigüedad, propiciando con esto un paisaje de indefensión y violación sistemática a derechos humanos en el país. Ahora bien, con la intención de caracterizar dicho paisaje, y de manera específica el impacto que generó la práctica de la desaparición forzada por parte de elementos de las fuerzas armadas, a continuación describiré dos antecedentes centrales que permiten dar cuenta de la apuesta por parte del Estado mexicano en torno dicha estrategia: el acuerdo binacional Iniciativa Mérida, y el Operativo Conjunto Chihuahua-Juárez.

\section{LA INICIATIVA MÉRIDA}

No se puede comprender el escenario actual de irrupción de la violencia en la zona fronteriza entre México y Estados Unidos, así como las estrategias de "seguridad pública" llevadas a cabo por el

5 El autor ejemplifica esta problemática de vacío legal en torno a la relación prevenciónreacción, respecto al surgimiento en agosto de 2014 de la Gendarmería como unidad operativa de la Policía Federal, a cargo de implementar operativos en aquellas zonas en las que exista presencia de la delincuencia organizada o altos índices delictivos. 
gobierno mexicano, sin tener presente el acuerdo binacional denominado Iniciativa Mérida. En Marzo de 2007, durante el encuentro que sostuvieron los presidentes Felipe Calderón y George Bush en la ciudad de Mérida, se formalizó el plan de apoyo logístico y financiero de seguridad, considerado como un esquema de cooperación bilateral entre México y Estados Unidos, que permitiría fortalecer y complementar los esfuerzos internos contra la delincuencia organizada transnacional.

"Los gobiernos de México y Estados unidos, comparten una profunda preocupación por la amenaza que representa para nuestras sociedades la operación de organizaciones criminales que actúan en ambos lados de nuestra frontera común. La creciente capacidad operacional y financiera de los grupos criminales involucrados en el tráfico de drogas, armas y personas, así como de otras actividades criminales trasnacionales, representan una contundente amenaza para las vidas y el bienestar de los ciudadanos de México y Estados unidos. Ambos países establecerán como una prioridad combatir el poder y la impunidad de las organizaciones criminales y del narcotráfico, que amenazan la salud y la seguridad pública de sus ciudadanos, así como la estabilidad y la seguridad de la región." (SRE, México, 2007)

El acuerdo destacó en su momento tres ejes de acciones: 1) reforzar los esfuerzos internos de procuración de justicia en México; 2) reforzar los esfuerzos internos de procuración de justicia en Estados Unidos; y 3) ampliar la cooperación bilateral y regional dirigida a la amenaza que representa la delincuencia transnacional organizada (SRE, México, 2007). En específico, destacó la prioridad de favorecer la adquisición de equipo militar de vigilancia, ${ }^{7}$

6 Dicho enfoque se fundamenta en la perspectiva que el Gobierno Federal de México planteó en el 2007, como parte de su política exterior a cargo de la Secretaría de Relaciones Exteriores. Consultar en https://embamex.sre.gob.mx/suecia/index.php/en/ comunicados/6-comunicados-2007/306--sp-998823279

7 Para el 2010, Estados Unidos había destinado \$1.5 mil millones en asistencia para México bajo la Iniciativa Mérida con el fin de combatir el tráfico de drogas y la violencia asociada al mismo, incluyendo asistencia para la reforma judicial, el desarrollo institucional, la lucha anticorrupción y el fomento del Estado de Derecho. Se estima 
(DES)MILITARIZACIÓN Y VIOLENCIA POLÍTICA: DESAPARICIÓN FORZADA...

así como el adiestramiento y capacitación de mandos militares y policiacos pertenecientes al Estado mexicano:

...para incrementar las capacidades operativas, nuestras estrategias incluyen una renovada transferencia de equipo y recurso técnico, de acuerdo con las normas correspondientes de transparencia y rendición de cuentas de ambos países. Asimismo, la estrategia incluye programas de capacitación e intercambio de expertos, pero no contempla el despliegue de personal militar estadounidense en México ${ }^{8}$ (SRE, México, 2007).

De manera particular, el acuerdo buscó considerar "un compromiso de protección y/o defensa de derechos humanos y establecer mecanismos para una relación continua con la sociedad civil" (Woodrom Wilson International Center, 2009). Aquí radica una de las preocupaciones fundamentales del gobierno de los Estados Unidos, el problema de la corrupción en los organismos de seguridad pública en México y la violación sistemática de los derechos humanos (Chabat, 2010). El estudio "Abuso y miedo en Ciudad Juárez: un análisis de violaciones a los derechos humanos cometidas por militares en México" de Meyer, Brewer y Cepeda (2010), es claro y contundente al mostrar el fracaso que significó en su momento la implementación de este acuerdo bilateral, en su compromiso de garantizar la defensa de los derechos humanos.

El rol de las fuerzas armadas como principal actor en los operativos antidroga ha llevado a un aumento en los abusos dada la impunidad de la que históricamente han gozado las fuerzas castrenses mexicanas. Pero también hay otros peligros asociados a la participación de los militares en operaciones de seguridad

que entre 2008 y 2010 el Departamento de Defensa de Estados Unidos destinó \$80.9 millones a financiar la lucha antidroga en México (Meyer, Brewer y Cepeda, 2010).

8 Si bien en el acuerdo se estableció el "no despliegue de personal militar estadounidense en México", considerado el "pleno respeto de la soberanía, la jurisdicción territorial y el marco legal de cada país; y están orientados por los principios de confianza mutua, responsabilidad compartida y reciprocidad." (Iniciativa Mérida, 2007). Varias notas periodísticas han evidenciado la participación de elementos de organismos como la DEA o el FBI, en diversos operativos de búsqueda y detención de personas que se consideraban vinculadas al narcotráfico. 
pública relacionados con las diferencias en entrenamiento y mandato entre las fuerzas. Las fuerzas armadas están entrenadas para actuar en situaciones de combate, en las cuales el objetivo es eliminar al enemigo mediante el uso de la fuerza sin consideración alguna por el bienestar del enemigo. Por el contrario, las fuerzas policiales están entrenadas para interactuar con civiles dentro de un marco básico de derechos constitucionales. Debido a las diferencias en cuanto a roles y tácticas, los conflictos y abusos son prácticamente inevitables cuando se asigna a los militares tareas que corresponden a la policía. Aparte genera serias dudas acerca de la práctica actualmente extendida de nombrar a militares en cargos de mando en las fuerzas policiales locales (Meyer, Brewer y Cepeda, 2010: 10).

En el año 2006, al ser electo presidente de la República el Lic. Felipe Calderón Hinojosa, llevó a la práctica la participación directa de comandos militares en torno a tareas de seguridad pública en diversas regiones del país. Los operativos conjuntos, fueron estrategias que se caracterizaron por una falta de coordinación entre diversos gobiernos locales y el gobierno federal, ante el incremento de la violencia expresada en un número creciente de homicidios dolosos, feminicidios, ${ }^{9}$ secuestros, y presencia de grupos vinculados al narcotráfico.

\section{OPERATIVO CONJUNTO CHIHUAHUA-JUÁREZ}

El 21 de marzo de 2008, el entonces secretario de Gobernación Juan Camilo Mouriño, anunció el inicio de la estrategia de seguridad pública denominada Operativo Conjunto Chihuahua-Juárez, con el que se desplazarían a esta ciudad fronteriza más de dos mil efectivos militares para contribuir al resguardo de la ciudad junto con las policías estatal y municipal. Tan solo cinco días después

9 En particular, el fenómeno del feminicidio ha sido un aspecto central para comprender el contexto de violencias que se ha gestado por años en la frontera. Julia Monárrez acuña la categoría "feminicidio sexual sistémico" para develar, bajo una lógica patriarcal, "la condición de sujeto matable de la mujer" (Monárrez, 2019). A partir de diversas fuentes de consulta, muestra el dato contundente al respecto, ya que contabiliza de 1993 a 2018, 1850 casos de mujeres y niñas asesinadas en Ciudad Juárez. 
del anuncio, los militares asumieron el control de las instalaciones y funciones de seguridad pública del estado y el municipio. En junio del mismo año, el gobierno federal anunció el despliegue de otros dos mil elementos castrenses, y para inicios de 2009 existían en la ciudad más de siete mil efectivos del ejército que tenían a su mando el control y tareas de vigilancia de la ciudad (Salazar y Curiel, 2012).

El discurso oficial en relación a incorporar militares en actividades de seguridad pública, constituye uno de los ejes clave del proceso de militarización que se promovió por medio de los operativos conjuntos en diversos lugares del país. En el 2009, el Ejecutivo Federal pronunciaba las siguientes palabras ante elementos del ejército adscritos al Operativo Conjunto Chihuahua: "En Ciudad Juárez derrotaremos al crimen organizado, porque nuestras Fuerzas Armadas no se arredrarán ni desistirán jamás”. ${ }^{10}$ El uso retórico que buscó legitimar las acciones directas de confrontación con los cárteles del narcotráfico, alcanzó su expresión más contundente en la expresión "guerra contra el crimen organizado”. Una política belicista por parte del gobierno federal, transitó como diáspora a diversos escenarios de la administración estatal en regiones del país. Para el caso específico de Chihuahua, la constante fue el llamado al gobierno federal para la participación de efectivos militares en tareas de seguridad pública, bajo la justificación de la infiltración del crimen organizado y el narcotráfico en las policías locales.

Si bien el uso legítimo de la fuerza, por organismos de cualquier Estado moderno democrático, parte de una necesidad básica y fundamental: "que no sean los particulares quienes resuelvan sus diferencias por propia mano y bajo sus propias reglas, sino que sea una entidad distinta la que resuelva dichas controversias, aun empleando la fuerza" (Guerrero Agripino y De Santiago Álvarez, 2013:35), el problema es el uso indiscriminado de la fuerza que, en palabras de Ernesto López Portillo: "la salida de las fuerzas

10 Boletín Presidencia de la República "Junto con el ejército, derrotaremos en Juárez al crimen organizado: Presidente Calderón”. En Presidencia de la República (sitio oficial), 14 mayo del 2009. http://calderon.presidencia.gob.mx/2009/05/junto-con-el-ejercito-derrotaremos-en-juarez-al-crimen-organizado-presidente-calderon/ 
armadas a las calles a realizar las tareas de seguridad pública, invierte el principio del uso racional de la fuerza, dominante en el mundo democrático contemporáneo, al ubicar el instrumento del uso máximo de la fuerza en el papel de recurso regular, multiplicando ad infinitum los riesgos del exceso" (López Portillo, 2016:07).

Ejemplo de ello es que al transcurrir los primeros meses de implementación del operativo, la Comisión Estatal de los derechos humanos del estado de Chihuahua, dio cuenta de un número de 1422 quejas en relación a diversos actos de violación a Derechos Humanos por parte de integrantes de las corporaciones policiacas y del ejército: ${ }^{11}$ allanamiento de morada, detención ilegal, robo, tortura, amenazas, desaparición forzada, incomunicación, entre otras. Al respecto, la perspectiva crítica de los derechos humanos (Gallardo, 2010) sostiene un cuestionamiento a la fragilidad de los Estados, que han producido una sociedad fracturada, una economía excluyente y la entronización de elites de gobiernos a partir de instrumentos de coerción, como ha sido la participación del ejército en diversas actividades de seguridad pública en franca violación a los derechos humanos.

En el 2009 Human Rigths Watch publicó un documento titulado "Impunidad Uniformada. Usos indebidos de justicia militar en México para investigar abusos cometidos durante operativos contra el narcotráfico y de seguridad pública”. En él detalla un panorama de prácticas violatorias por parte de militares a la población en general a partir de la "desaparición forzada". El documento dio cuenta que:

"México ha utilizado a las fuerzas armadas en operativos contra el narcotráfico y la insurgencia durante décadas. No obstante, la visibilidad de las fuerzas armadas en operaciones de seguridad pública ha incrementado drásticamente durante el gobierno de Calderón, quien ha planteado el despliegue del Ejército como una de sus estrategias clave para combatir al narcotráfico y mejorar la seguridad pública.

11 Referencia "Suman 1450 quejas contra el ejército" publicada en el periódico El Universal, el 10 de septiembre de 2009. Consultar en https://archivo.eluniversal.com.mx/ estados/73044.html 
Miles de integrantes de las fuerzas armadas han sido incorporados a la policía federal y más de 40.000 efectivos entre militares y policías han sido asignados a distintas partes del país. En ciudades muy violentas, como Ciudad Juárez y Tijuana, los gobiernos locales han designado a militares de alto rango al frente de la policía. Si bien el gobierno de Calderón ha señalado que el uso del Ejército es de carácter temporal, aún no ha presentado siquiera un plan provisional para el repliegue de las tropas..." (Human Rigths Watch, 2009: 02).

En general, podemos concluir que la implementación de operativos policiaco-militares como el Operativo Conjunto ChihuahuaJuárez, fueron resultado de una política a gran escala de impulso a la militarización de la seguridad pública en diversas regiones del país. Ante la presión interna por parte de diversos sectores de la población, que enfrentan el colapso de sus experiencias cotidianas resultado del incremento de violencias, así como externa, como da cuenta el acuerdo Iniciativa Mérida, el Estado mexicano ha promovido una estrategia de subordinación de las corporaciones policiacas municipales a una estructura jerárquica y de mando militar, resultando con ello una crisis sistémica en relación a los derechos humanos.

\section{LA DESAPARICIÓN FORZADA COMO DISPOSITIVO DE NECROPODER}

En los últimos años, uno de los fenómenos de mayor preocupación en México ha sido el de personas extraviadas o desaparecidas. ${ }^{12}$ Un número importante de estos casos, como bien lo dan a conocer diversos abordajes periodísticos, ${ }^{13}$ están vinculados al

12 El Registro Nacional de Datos de Personas Extraviadas o Desaparecidas (RNPED), del Secretariado Ejecutivo del Sistema Nacional de Seguridad Pública, reconoce entre enero de 2014 y abril de 2018 en todo el país, un total de 37435 casos. Vale la pena destacar que el 63\% corresponde a población en el rango de edad de 15 a 34 años. Consultar en https://www.gob.mx/sesnsp/acciones-y-programas/registro-nacional-dedatos-de-personas-extraviadas-o-desaparecidas-rnped

13 El 31 de agosto de 2019, El Heraldo de Chihuahua publicó una nota titulada "Hay 306 fosas clandestinas en Chihuahua". En ella da cuenta, a partir de datos generados por la Comisión Nacional de Búsqueda de la Secretaría de Gobernación, que la entidad ocupa uno de los primeros lugares a nivel nacional en torno al fenómeno, y que varios

Chinuahua Hoy, aÑo i 8, núm. I8 (ENERO-Diciembre, 2020) 
mundo del narcotráfico y el crimen organizado, como resultado del reclutamiento forzoso que se genera sobre diversos sectores de la población, principalmente jóvenes (De la O y Flores, 2012). Sin embargo, existe otro escenario en el que diversas evidencias han dado cuenta, que elementos adscritos a los organismos de seguridad pública y de las fuerzas armadas, han contribuido de manera sistémica a este tipo de práctica.

En particular, el estado de Chihuahua ha enfrentado un número importante de casos de desaparición forzada, que no se limitan a aquellos acontecidos durante la puesta en marcha del Operativo Conjunto. Al respecto Víctor Quintana (2013) remite al antecedente de la llamada "guerra sucia" gestada por el Estado mexicano contra diversas organizaciones populares que en la década de los setenta y ochenta fueron claves en la movilización social de la región. Aunado a ello, la creciente presencia y poder del narcotráfico, sumado a una severa crisis de legitimidad en los gobiernos municipales y estatal resultado de la corrupción y la impunidad que se gestaba en un número a la alza de casos de homicidios y feminicidios en la frontera, fueron el caldo de cultivo para que este tipo de práctica se halla generalizado en la región.

Un factor que se presenta en la gran mayoría de desapariciones, y que a su vez se convierte en lo que posibilita la multiplicación de las mismas, es la impunidad. El hecho de que la mayoría de desapariciones forzadas queden sin castigo, viene a ser un incentivo para repetir esa práctica criminal. Si el Ejército no tuvo ningún tipo de sanción por las desapariciones forzadas de tiempos de la "guerra sucia"; si tampoco se le sancionó ni a él ni a las policías estatales por las desapariciones de fines de los ochenta y principios de los noventa, entonces el Estado está enviando un mensaje muy claro entre líneas: la forma menos riesgosa de prescindir de alguien que estorba es la desaparición forzada, pues en una mínima parte de los casos se castiga. Además, los perpetradores de dicha desaparición tienen la seguridad de que, mientras

de estos casos están relacionados con la práctica de desaparición de personas por parte del crimen organizado. 
no aparezca la persona, el miedo hará que sus familiares guarden silencio" (Quintana, 2013: 545)

En esta línea, podemos dar cuenta que el fenómeno de la desaparición forzada no es una práctica aislada o esporádica por parte de elementos adscritos a los organismos de seguridad pública del Estado mexicano, sino la expresión contundente de una política intencional, en la que criterios de selectividad sobre aquellos cuerpos eliminables ha sido una constante en diversos operativos. Es decir, la desaparición forzada ha constituido un dispositivo necropolítico ${ }^{14}$ de administración y producción de la muerte por parte del Estado mexicano, valiéndose del creciente uso de la fuerza para someter y aniquilar cuerpos, en su interés de sostener una retórica belicista como parte de su perspectiva en torno a la seguridad pública. Ariadna Estévez sostiene que en México:

Las muestras públicas de violencia extrema, tales como masacres, con el objeto de intimidar, someter cuerpos a tortura, ejecuciones, desaparición forzada, persecución y muerte tienen el objetivo de hacer morir en enclaves territoriales de pobreza, corrupción, impunidad y escasa presencia institucional del Estado, donde el reto es sobrevivir (Estévez, 2018: 04).

Según la Declaración sobre la protección de todas las personas contra las desapariciones forzadas, proclamada por la Asamblea General de la ONU el 18 de diciembre de 1992, como conjunto de principios que deben ser aplicados por todos los Estados, se producen desapariciones forzadas siempre que:

14 La categoría de necropolítica del filósofo camerunés Archille Mebmebe (2011), ha permitido dar cuenta de las prácticas por las que se mantiene el control sobre quienes deben vivir, y quienes deben morir. Plantea una discusión central en cómo el estado de excepción, y la relación de enemistad o de caracterización del enemigo, se establecen para posibilitar el desarrollo de la necropolítica. Si bien, ubica su discusión en los procesos de colonización que significaron la imposición violenta de la civilización occidental en gran parte de África, para nuestros intereses adquieren relevancia ya que permite anclar la relación entre militarización y violencia política como mecanismo para establecer el ejercicio del poder en torno a los cuerpos más precarizados y vulnerables. 
...el arresto, la detención, el secuestro o cualquier otra forma de privación de libertad que sean obra de agentes del Estado o por personas o grupos de personas que actúan con la autorización, el apoyo o la aquiescencia del Estado, seguida de la negativa a reconocer dicha privación de libertad o del ocultamiento de la suerte o el paradero de la persona desaparecida, sustrayéndola a la protección de la ley (ONU, 1992).

Como podemos observar, constituye un acto cuya principal intención es "la negativa del derecho de un individuo a existir, a tener una identidad, convertir a una persona en un ser no existente." (Parayre, 1999; 26). Desde el punto de vista jurídico, la Convención Interamericana sobre Desaparición Forzada de Personas toma en consideración varios aspectos que deben estar presentes en aquellos eventos que busquen tipificarse en este sentido: que se haya privado a una persona de la libertad en cualquier forma; que esa privación de libertad haya sido ejecutada por agentes del Estado o personas o grupos de personas que actúan con su autorización, apoyo o aquiescencia; que la privación de libertad haya sido seguida de la falta de información o negativa a reconocer la privación de libertad o de informar sobre el paradero de la persona; y, que a consecuencia de lo anterior se haya impedido a la persona ejercer los recursos legales y las garantías procesales pertinentes (OEA, 1994).

Para el caso específico en México, se ha generado un debate importante frente a las problemáticas jurídico-procedimentales que ha significado el reconocimiento y la atención al fenómeno de la desaparición forzada por agentes del Estado (Guzmán-Vera, 2018). Si bien no es nuestra intención plantear una discusión desde la mirada normativa, y con el objetivo de centrar nuestro análisis en la práctica generada por agentes del Estado en el contexto de los operativos conjuntos, no podemos perder de vista que especialistas en el tema señalan el problema de la ambigüedad que presenta la desaparición forzada en los marcos legales que regulan la sanción y castigo a los agentes del Estado (Guevara y 
(DES)MILITARIZACIÓN Y VIOLENCIA POLÍTICA: DESAPARICIÓN FORZADA...

Chávez, 2018), así como los mecanismos de reparación del daño que estarían obligados a llevar a cabo ante las víctimas.

\section{DESAPARICIÓN FORZADA ANTE LA CORTE IDH: CASO ALVARADO VS. ESTADO MEXICANO}

Resultado de la puesta en marcha del Operativo Conjunto Chihuahua-Juárez, entre los años 2009 y 2012 se presentó en el estado fronterizo de Chihuahua el endurecimiento de la estrategia de militarización de la seguridad pública, dando como resultado que en diversas regiones de la entidad la práctica de la desaparición forzada, acompañada de otros mecanismos de represión como la tortura, fuera una constante por parte de agentes del Estado frente a diversos sectores de la población.

El 28 de noviembre de 2018, la Corte IDH con sede en San José de Costa Rica, emitió la sentencia definitiva en torno al caso Alvarado Espinoza y otros vs. México. ${ }^{15}$ En dicho documento se describe con puntualidad el proceso jurídico con duración de nueve años, a partir de la denuncia que integrantes de la familia Alvarado llevaron a cabo en diversas instancias judiciales del Estado mexicano, en relación a la detención arbitraria y desaparición forzada de tres integrantes de su familia por parte de elementos del ejército vinculados al Operativo Conjunto Chihuahua-Juárez.

La sentencia da cuenta de una serie de violaciones sistemáticas generadas por diversos organismos de seguridad pública, corporaciones de las fuerzas armadas, así como instancias encargadas de los procedimientos judiciales en torno al caso. En general, sostiene que:

La Corte constató que el incremento en la participación del Ejército en las labores de seguridad ciudadana ha sido un patrón constante en México desde el año 2006. En dicho escenario, el empleo de las

15 En dicho proceso de resolución y sentencia, de acuerdo a las facultades establecidas en la Convención Americana sobre Derechos Humanos, participaron como jueces respectivos del caso: Eduardo Vio Grossi, Humberto Antonio Sierra Porto, Elizabeth Odio Benito, Eugenio Raúl Zaffaroni, y Patricio Pazmiño Freire. Para mayor referencia consultar: http://www.corteidh.or.cr/docs/casos/articulos/seriec_370_esp.pdf 
fuerzas castrenses en la lucha contra la delincuencia se convirtió en una práctica recurrente mediante la implementación de los denominados "Operativos Conjuntos" en cuya intervención concurrían efectivos policiales y militares. Lo anterior, sin haberse acreditado, para efectos del caso concreto, que se hubieran respetado salvaguardias para la participación de las fuerzas armadas, tales como la: excepcionalidad, temporalidad y estricta necesidad del operativo conjunto, así como una adecuada regulación y protocolos de actuación para tales tareas ni su fiscalización, e inclusive ventilándose los hechos denunciados en el fuero militar por un periodo de tiempo considerable. En vista del análisis expuesto, la Corte concluye que el Estado mexicano es internacionalmente responsable por la desaparición forzada de Nitza Paola Alvarado Espinoza, José Ángel Alvarado Herrera y Rocío Irene Alvarado Reyes, en violación de los derechos al reconocimiento de la personalidad jurídica, a la vida, a la integridad personal y a la libertad personal establecidos, respectivamente, de conformidad con la Convención Americana y de la Convención Interamericana sobre Desaparición Forzada de Personas (Fragmento sentencia Corte IDH, 2018: 78).

\section{LA DESAPARICIÓN DE LOS TRES INTEGRANTES DE LA FAMILIA ALVARADO}

El 9 de noviembre de 2016 la Comisión Interamericana de Derechos Humanos sometió a la jurisdicción de la CIDH el caso "Alvarado Espinoza y otros vs. México”, en torno a la desaparición forzada y otras violaciones por parte de agentes de las Fuerzas Armadas, de Nitza Paola Alvarado Espinoza, José Ángel Alvarado y Rocío Irene Alvarado Reyes, en el Ejido Benito Juárez, estado de Chihuahua, México, el día 29 de diciembre de 2009. El documento de la sentencia, respaldado por una serie de declaraciones generadas por integrantes de la familia Alvarado y miembros de la comunidad del Ejido, describe con claridad cómo fue la participación de una unidad militar en la detención de las tres personas. 
El 29 de diciembre de 2009, entre las 8:00 y 9:00 de la noche, José Ángel Alvarado Herrera y Nitza Paola Alvarado Espinoza se encontraban a bordo de una camioneta azul marino, doble cabina, estacionada en las afueras de la casa de la madre de Obdulia Espinoza Beltrán, esposa de José Ángel, en el Ejido Benito Juárez. En ese momento, arribaron al lugar dos camionetas particulares, una de ellas marca Chevrolet, doble cabina, color gris, diésel, y la otra marca Hummer, color blanco, de las cuales descendieron entre ocho y diez personas portando armas largas, cascos y gorras, sin pasamontañas, así como uniformes de tipo militar, algunos de color arena camuflado, "caqui como café" "de tipo desierto" y botas del mismo color, y otros de color verde y quienes los portaban tenían un acento de voz distinto al de los habitantes de la zona. Dichos sujetos se dirigieron en su mayoría hacia el lado del conductor, en donde se encontraba Nitza Paola, mientras otro de ellos se dirigió hacia José Ángel, quien había descendido de la camioneta y se encontraba de pie junto a la cabina. Los elementos procedieron a revisar el vehículo y luego de un intercambio de palabras tomaron a Nitza Paola de los cabellos para obligarla a bajar del mismo y cuando José Ángel intentó defenderla, el sujeto que se encontraba a su lado lo golpeó en la cara con el arma que portaba, tras lo cual subieron a ambos familiares a la parte posterior de la camioneta doble cabina en que los captores arribaron al lugar de los hechos, retirándose con rumbo desconocido (Fragmento sentencia Corte IDH, 2018: 29).

El fragmento describe la forma arbitraria en la que José Ángel Alvarado y Nitza Paola Alvarado fueron detenidos, sin orden judicial y con desproporcionado uso de la fuerza. En relación a Rocío Irene Alvarado Reyes, el documento da cuenta de:

El 29 de diciembre de 2009, alrededor de una hora después de la detención de Nitza Paola y José Ángel Alvarado, siendo aproximadamente las 9:00 o 10:00 de la noche, Rocío Irene Alvarado Reyes se encontraba descansando en compañía de sus dos hermanos, de su hija de 2 años de edad, y de su madre Patricia Reyes Rueda en su domicilio en el Ejido Benito Juárez. En ese momento, la señora 
Reyes Rueda escuchó que unas personas arribaron a su domicilio, por lo que procedió a asomarse por la puerta de la cocina en compañía de su hija Rocío Irene y observó que se trataba de individuos que vestían uniformes con características militares quienes golpearon la puerta de la entrada de la vivienda, y gritaron que ésta les fuera abierta o de lo contrario "la iban a tirar". Ingresaron entre 8 y 9 personas encapuchadas portando vestimenta militar, cascos y armas largas con lámpara, mismos que tras detener a su familiar se retiraron en una camioneta Pick up, diésel, de cabina y media, gris o negra y sin focos. La señora Reyes Rueda preguntó a los elementos el motivo por el cuál su hija Rocío Irene estaba siendo arrestada, a lo que contestaron ordenándole que guardara silencio. Antes de su partida, Rocío Irene manifestó a sus familiares "que no se preocuparan", "que todo iba a estar bien", y "que enseguida volvería", tras lo cual salió del domicilio a manos de sus captores. A la fecha, el paradero de Rocío Irene Alvarado ha sido desconocido (Fragmento sentencia Corte IDH, 2018: 31).

A las pocas horas de la detención, varios miembros de la familia comenzaron a realizar la búsqueda de los tres integrantes. Se trasladaron a la Comandancia de Seguridad y Vialidad Pública del Ejido Benito Juárez, así como a las instalaciones del 35 Batallón de Infantería del ejército, ubicado en el poblado de Nuevo Casas Grandes, Chihuahua, y a la Agencia Estatal de Investigaciones de la Procuraduría General del Estado, ubicada en esta localidad. Tras entrevistarse con funcionarios adscritos a estas dependencias, tuvieron como respuesta el desconocimiento o la negación de la detención de los tres familiares. En este sentido, valdría la pena enfatizar que una de las características de la desaparición forzada, es la negación de la condición de víctima por parte de funcionarios del Estado:

De acuerdo con la jurisprudencia de esta Corte, una de las características de la desaparición forzada, a diferencia de la ejecución extrajudicial, es que conlleva la negativa del Estado de reconocer que la víctima está bajo su control y de proporcionar información 
al respecto, con el propósito de generar incertidumbre acerca de su paradero, vida o muerte, de provocar intimidación y supresión de derechos. Sobre este elemento de la desaparición forzada en el caso concreto, la Corte nota que tras la detención de las 3 víctimas los familiares iniciaron diversas denuncias y acciones de búsqueda en donde, no obstante la información proporcionada a estos por diversos agentes estatales, los funcionarios negaron que los detenidos se encontraran bajo custodia estatal o en dependencias oficiales y les informaron que no tenían información sobre su paradero (Fragmento sentencia Corte IDH, 2018: 77).

Otro punto relevante, fue la evidencia contundente del fenómeno de desplazamiento forzado que varios integrantes de la familia Alvarado enfrentaron, resultado de amenazas constantes por parte de integrantes de corporaciones de policía y elementos del ejército.

...la Corte acreditó que los distintos grupos familiares se han visto en la necesidad de realizar diversos desplazamiento en el territorio nacional y otros fuera de este. En vista de lo anterior, este Tribunal estima que para el momento del desplazamiento de los grupos familiares, era evidente que las autoridades tenían conocimiento de que habían ocurrido actos de amenazas y que el contexto y demás elementos del caso permitían establecer la posibilidad concreta de su realización (Fragmento sentencia Corte IDH, 2018: 95).

En general, la resolución por parte de la Corte IDH da cuenta de una serie de violaciones sistemáticas a los derechos humanos, que constituyen evidencia de la estrategia fallida que significó la participación de fuerzas armadas en materia de seguridad pública durante el tiempo que se desarrolló el Operativo Conjunto. Da cuenta de violaciones generadas por agentes del Estado mexicano a derechos como el reconocimiento de la personalidad jurídica, a la vida, a la integridad personal y a la libertad personal, circulación y residencia, considerados en la Convención Americana de los Derechos Humanos, así como el de desaparición forzada 
contemplada en la Convención Interamericana sobre Desaparición Forzada de Personas. ${ }^{16}$

\section{IMPLICACIONES EN LA RESOLUCIÓN DE LA SENTENCIA}

El caso Alvarado Espinoza, como bien han señalado diversos organismos vinculados a la defensa de los derechos humanos, ${ }^{17}$ constituye la primera puesta en escena internacional ante la Corte Interamericana de Derechos Humanos, ${ }^{18}$ de la puesta en marcha de la estrategia de militarización de la seguridad pública, y en particular un antecedente en torno a la invalidación de la "Ley de Seguridad Interior" por parte de la Suprema Corte de Justicia de la Nación, ${ }^{19}$ aprobada por el poder legislativo y ejecutivo en diciembre de 2017. Un marco normativo fuertemente cuestionado, ya que evidenció cómo "sectores de la población y organismos internacionales encontraron en ella razones suficientes para argumentar que pondría en peligro justamente el orden público, cuya base es la principal garantía individual del gobernado: la paz pública" (Reyna, 2019: 47). En un informe publicado en el 2017, Justicia olvidada: la impunidad de las violaciones a derechos humanos cometidas por soldados en México, ${ }^{20}$ el organismo The Washington Office on Latin

16 Ratificada por México el 9 de abril de 2002.

17 El Centro por la Justicia y el Derecho Internacional (CEJIL) con sede en San José de Costa Rica, planteó en un comunicado que dicho caso constituye un antecedente fundamental en la evidencia de la violación sistemática a los derechos humanos en México, en torno a la participación del ejército en tareas de seguridad pública. Consultar en https://www.cejil.org/es/caso-alvarado-primero-que-corte-interamericana-sepronunciara-ley-seguridad-interior-mexico

18 También conocida como Pacto de San José de Costa Rica, y suscrita el 22 de noviembre de 1969, y ratificada por México el 2 de marzo de 1981.

19 El 15 de noviembre de 2018, con 9 votos a favor y uno en contra, ministros de la Suprema Corte de Justicia de la Nación declararon la inconstitucionalidad de la Ley de Seguridad Interior, aprobada un año antes por el gobierno federal, por considerar que viola diversos preceptos de la Constitución Política de los Estados Unidos Mexicanos. Comunicado No. 149/2018, disponible en: http://www.internet2.scjn.gob.mx/red2/comunicados/noticia.asp?id=5794.

20 El informe da cuenta de una serie de delitos y violaciones cometidas por elementos de las fuerzas armadas en tareas de seguridad pública. Destacan eventos vinculados a tortura, abuso de autoridad, desaparición forzada, homicidio, y lesiones, entre otros. (Documento disponible en https://www.wola.org/wp-content/uploads/2017/11/ WOLA_MILITARY-CRIMES_RPT_SPANISH.pdf) 
America (WOLA), dio cuenta de las serias amenazas que significó la participación del ejército en tareas de seguridad pública, y las razones por las que no es aceptable un marco jurídico que busque legalizar su presencia al respecto.

La estrategia de seguridad militarizada ha tenido al menos tres consecuencias graves. La primera es que la violencia ha aumentado en México y las violaciones a derechos humanos son constantes; la segunda es que ha disminuido la urgencia y la presión de una reforma policial; y la tercera es que la rendición de cuentas ha sido prácticamente inexistente. Los soldados que cometen delitos y violaciones a derechos humanos generalmente no responden por sus acciones, tampoco los funcionarios públicos que solicitan la presencia de soldados en sus estados o municipios, ni los líderes políticos que por décadas no se han comprometido verdaderamente a mejorar a la policía en México (WOLA, 2017: 8).

Ante dicho panorama, la resolución emitida por la Corte IDH en torno al caso Alvarado, constituye una llamada de alerta a las intenciones del Estado mexicano de buscar implementar mecanismos jurídicos en la participación de las fuerzas armadas en tareas de seguridad pública.

...la Corte reafirma que el mantenimiento del orden público interno y la seguridad ciudadana deben estar primariamente reservados a los cuerpos policiales civiles. No obstante, cuando excepcionalmente intervengan en tareas de seguridad, la participación de las fuerzas armadas debe ser: a) Extraordinaria, de manera que toda intervención se encuentre justificada y resulte excepcional, temporal y restringida a lo estrictamente necesario en las circunstancias del caso; b) Subordinada y complementaria, a las labores de las corporaciones civiles, sin que sus labores puedan extenderse a las facultades propias de las instituciones de procuración de justicia o policía judicial o ministerial; c) Regulada, mediante mecanismos legales y protocolos sobre el uso de la fuerza, bajo los principios de excepcionalidad, proporcionalidad y absoluta necesidad y de acuerdo con la respecti- 
va capacitación en la materia; y, d) Fiscalizada, por órganos civiles competentes, independientes y técnicamente capaces (Fragmento sentencia Corte IDH, 2018: 70).

Como bien muestra el fragmento de la resolución, la Corte IDH es clara en señalar cuatro principios centrales en los límites y control de actuación de las fuerzas armadas en tareas reservadas a la policía civil -extraordinaria, subordinada y complementaria, regulada, y fiscalizada-. En este sentido, lo que se ha presentado en los últimos años en el país, y considerando en específico la puesta en marcha de los operativos conjuntos en diversas regiones, estos principios no han sido considerados por parte del Estado mexicano, dando como resultado el incremento de la violencia política y una continua violación sistemática a derechos humanos a diversos sectores de la población:

La Corte constata que la implementación del Operativo Conjunto materia de este caso, no contaba con una regulación o aplicación que previera la excepcionalidad y temporalidad de la actuación militar, así como demás salvaguardias frente a este tipo de intervenciones, menos aún con una fiscalización independiente de sus operaciones, como quedó demostrado, entre otras probanzas, con las quejas interpuestas ante el propio "Programa de Atención y Quejas" del "Operativo" y la remisión del caso a la jurisdicción militar (Fragmento sentencia Corte IDH, 2018: 71).

Si bien la puesta en marcha de los operativos conjuntos se desarrolló en gran medida durante los periodos de las administraciones federales de los presidentes Lic. Felipe Calderón Hinojosa y Lic. Enrique Peña Nieto, esto no ha significado un cambio en la actual administración encabezada por el Lic. Andrés Manuel López Obrador. Considerado como un gobierno de "izquierda", constituyó una expectativa generalizada en el cambio de la estrategia de seguridad pública interna y la atención a víctimas de la violencia vinculada al narcotráfico, crimen organizado y aquella gestada por parte de organismos del Estado. A continuación, 
y teniendo presente el argumento central del texto en torno a cómo sigue reproduciéndose una lógica de necropoder por parte del Estado mexicano, se planteará un breve análisis en relación al surgimiento de un nuevo mecanismo de control denominado "Guardia Nacional".

\section{LA SIMULACIÓN EN EL CAMBIO DE ESTRATEGIA. EL SURGIMIENTO DE LA GUARDIA NACIONAL}

La palabra simulación, del latín simulatio, hace referencia a una alteración o modificación aparente de una causa. En esta línea, si bien el discurso oficial por parte de la administración federal actual ha planteado discursivamente un giro en la estrategia, considero que hechos recientes dan muestra del endurecimiento de la estrategia de control sobre ciertos sectores de la población. Efectivamente, el gobierno federal ha reconocido las implicaciones de una estrategia fallida, resultando como vimos al inicio del texto, en un desbordante incremento de casos de desaparición forzada. Si bien el representante del Ejecutivo ha planteado una perspectiva que desde la campaña presidencial expresó en la frase: "abrazos no balazos", ${ }^{21}$ y buscó dar un giro radical al enfoque de las administraciones anteriores, en los hechos se ha colocado un fuerte debate a la puesta en marcha de la agrupación Guardia Nacional, ${ }^{22}$ al considerar varios organismos que es una estrategia basada en la perspectiva contenciosa que encubre la continuidad del enfoque de militarización de la seguridad pública. Al respecto, "Propuesta de Guardia Nacional concretizaría la militarización de la seguridad pública en México”, Maureen Meyer de WOLA sostiene que:

21 Frase emitida en el 2018 durante el periodo de campaña a la presidencia de la República. Para mayor referencia consultar https://www.efe.com/efe/america/mexico/las-diez-frases-mas-sonadas-de-lopez-obrador-en-la-campana-electoral-mexicana/50000545-3644021

22 El 27 de mayo de 2019 en el Diario Oficial de la Federación se publicó la Ley de la Guardia Nacional, que en lo específico define los criterios operativos y de regulación al nuevo organismo en torno a actividades de seguridad pública. Si bien el documento en su Artículo 4 menciona que será un organismo de carácter civil, en la realidad se planteó un modelo de tránsito de cinco años bajo control y administración militar. 
Aunque el Plan Nacional reconoce la falta de capacidad y profesionalización que impacta las fuerzas policiales de México, en vez de centrarse en la reforma policial y poner fin a la dependencia que tiene México en las fuerzas armadas en el combate a la delincuencia, el gobierno de López Obrador transferiría las funciones policiales a una fuerza dirigida por militares. La Guardia Nacional propuesta asumirá las funciones tradicionales de una fuerza policial civil: prevenir y combatir el delito, detener a los sospechosos y coadyuvar en las investigaciones penales (Meyer, 2019)

Al revisar la visión que el gobierno federal establece en torno a este cuerpo policiaco-militar, encontramos que sostiene que su objetivo principal es: "realizar la función de seguridad pública a cargo de la Federación y, en su caso, colaborar temporalmente en las tareas de seguridad pública que corresponden a las entidades federativas o municipios" (Gobierno Federal, 2019). En la página oficial de dicha agrupación, se menciona que se caracteriza por dos lógicas de operación, "de campo" referida a aquella que involucra de manera directa en tareas de respaldo en combate o despliegue del uso de la fuerza, y "de proximidad" relacionada más a la atención directa a la población en escenarios de riesgo.

En junio de 2019, ante el incremento de grupos migrantes que arribaron a Ciudad Juárez, varios de ellos con la intención de solicitar ante las autoridades migratorias de los Estados Unidos proceso de asilo, el gobierno federal, a solicitud de los gobiernos estatal y municipal, y frente a la presión de la administración encabezada por Donald Trump, implementó un programa de respuesta contenciosa en la línea fronteriza con la participación activa de elementos del ejército. Como da cuenta el reportaje de Martín Orquiz "Relega Guardia Nacional plan anticrimen en Ciudad Juárez” publicado el 8 de septiembre por la plataforma periodística La Verdad Juárez, elementos del ejército participaron en la detención, bajo el uso desproporcionado de la fuerza, de grupos de migrantes para entregarlos a las autoridades migratorias y con ello iniciar el proceso de deportación. Si bien, en el último año no existe información puntual en relación a prácticas de desapa- 
rición forzada por parte de elementos del ejército, en particular a la población migrante, valdría la pena remitir a la discusión que Ariadna Estévez nombra como "dispositivo necropolítico de producción y administración de la migración forzada”, perfilando una lógica que da muestra de cómo en "la frontera el necropoder ejecuta políticas y leyes que deliberadamente intentan conducir hacia la muerte a solicitantes de asilo y deportados, y despoblar espacios geográficamente estratégicos, produciendo más migrantes" (Estévez, 2018: 02).

Este fenómeno se vincula a la problemática de la falta de “coordinación" por parte de los organismos de los gobiernos municipal, estatal y federal. Como fue el caso de la implementación de los operativos conjuntos, el análisis del que da cuenta la resolución de la Corte IDH respaldada por diversas fuentes de consulta y peritajes por parte de especialistas en el tema, evidencia la subordinación de la política de seguridad pública al control y mando de la estructura y visión militar (Padilla, 2019).

\section{CONCLUSIÓN}

Con la intención de cerrar en torno a los puntos aquí planteados, considero tres rutas de reflexión ante la crisis que ha implicado la puesta en marcha de la militarización de las tareas de seguridad pública por parte de Estado mexicano, y con ello la práctica sistematizada de violación a derechos humanos, con la finalidad de discutir, más allá del debate jurídico-procedimental, cómo se ha instaurado una lógica de estado de excepción como dinámica cotidiana en varias regiones de la entidad, enfrentando con ello a una sociedad sometida a las sensaciones de miedo, incertidumbre y autoestrategias de encierro.

Si bien en el caso de la desaparición forzada no se cuenta con registro reciente que vincule a elementos de la Guardia Nacional en operativos efectuados en el estado de Chihuahua, no podemos perder de vista que en los últimos meses se observa un incremento de homicidios dolosos, así como otras expresiones de violencia vinculadas a la presencia de narcomenudeo y el crimen 
organizado. Sumado a ello, el gobierno federal encabezado por Andrés Manuel López Obrador, ha hecho pública su intención de fortalecer las tareas de seguridad pública con la participación de las fuerzas armadas. Es un aspecto relevante que exige una mirada en retrospectiva y crítica ante la evidencia de lo que significó la participación de cuerpos castrenses en las administraciones anteriores, en acciones violatorias a derechos humanos.

Esto es relevante, ya que la perspectiva que aquí se ha planteado en relación a la apuesta del Estado mexicano en torno a fomentar la militarización de la seguridad pública, y considerando el caso específico de la resolución emitida por la Corte IDH en el caso Alvarado Espinoza y otros vs. México, da cuenta de la puesta en escena de un poder soberano que se establece a partir de criterios de selectividad en torno a la vida y la muerte. Como nos los señala Mbembe, "la expresión última de soberanía, reside ampliamente en el poder y la capacidad de decidir quién puede vivir y quién debe morir" (Mbembe, 2011). Si bien remitimos al caso específico de la familia Alvarado en el contexto de implementación del Operativo Conjunto, históricamente el uso de la violencia no legítima por parte de agentes del Estado mexicano, en particular asociada a la desaparición forzada y otras prácticas de tortura, en complicidad con otros actores como el crimen organizado, es la muestra contundente de una política basada en criterios selectivos en torno a la muerte.

Un segundo aspecto está relacionado a lo que Giorgio Agamben (2010), en su texto Estado de Excepción. Homo sacer II sostiene en relación a que esta figura que refiere a la suspensión del orden jurídico como medida provisional y de carácter extraordinaria, en las últimas décadas ha sido una constante, es decir, se ha constituido en un paradigma normal de los gobiernos. En el caso específico de nuestro texto, la caracterización alrededor de los operativos conjuntos-coordinados, así como la organización actual de la Guardia Nacional, dan cuenta de cómo el estado de excepción en la actualidad se ha vuelto norma. Como mencionamos al inicio, si bien el artículo 29 de la Constitución en México otorga facultades al poder ejecutivo para suspender garantías y 
derechos, bajo criterios de proporcionalidad en el uso de la fuerza, el paisaje reciente de violencia en el norte del país da muestra de cómo ha sido rebasada esta facultad y ha resultado en acciones de violación a derechos, incluso aquellos que claramente son contemplados y defendidos por el artículo en cuestión.

En este sentido, el caso aquí expuesto da cuenta de la práctica de violación a derechos, como ha sido el caso de la desaparición forzada. Observamos que un organismo como la Comisión Interamericana de Derechos Humanos ha mostrado una preocupación específica por este tipo de prácticas por parte de agentes del Estado mexicano. Si bien en los últimos dos años el gobierno federal ha promovido una política de reconciliación a cargo de Alejandro Encinas Rodríguez ${ }^{23}$ con familiares de víctimas relacionadas a este delito, no podemos dejar pasar que uno de los aspectos cruciales es el reconocimiento y la generación de políticas públicas de atención a las víctimas por parte de las administraciones estatales y municipales. Si bien el texto centró su atención en operativos coordinados por agentes adscritos a las administraciones federales, en el caso específico de Chihuahua es importante abordar la problemática de la desaparición forzada generada por organismos de seguridad a cargo de los gobiernos estatal y municipal. Solo a partir de ello se observará una intención clara del Estado mexicano de generar a mediano plazo un giro radical en la disminución de la violencia política, la eliminación de la impunidad frente a casos de desaparición generados por particulares, así como un horizonte de certidumbre en la reparación del daño y reconocimiento de las víctimas.

\section{BIBLIOGRAFÍA}

Cámara de Diputados del H. Congreso de la Unión. Ley general en materia de Desaparición Forzada de Personas, Desaparición cometida por Particulares, y del Sistema Nacional de Búsqueda de Personas. Diario Oficial de la Federación, México, 17-11-

23 Actual subsecretario de Derechos Humanos, Población y Migración, de la Secretaría de Gobernación, México. 
2017. Consultada el 3 de abril de 2020 en http://www.diputados.gob.mx/LeyesBiblio/pdf/LGMDFP_171117.pdf

CentroPRODH (2018). Diez preguntas clave sobre la Ley general en materia de Desaparición Forzada de Personas, Desaparición cometida por Particulares, y del Sistema Nacional de Búsqueda de Personas. Centro de Derechos Humanos Miguel Agustín Pro Juárez, México. Documento consultado el 10 de abril del 2020 en http://centroprodh.org.mx/wp-content/uploads/2018/12/Cartilla_LDF_Full.pdf

Corte IDH (2018). Caso Alvarado Espinoza y Otros vs. México. Sentencia de 28 de noviembre del 2018. Consultar en http:// www.corteidh.or.cr/docs/casos/articulos/seriec_370_esp.pdf

Chabat, J. (2010). La Iniciativa Mérida y la relación México-Estados Unidos: en busca de la confianza perdida. Documentos de trabajo CIDE, número 195. Consulta en http://libreriacide.com/ librospdf/DTEI-195.pdf

De la O, M. E. y Flores Ávila, A. L. (2012). “Violencia, jóvenes y vulnerabilidad en la frontera noreste de México”. Revista Desacatos, no.38, CIESAS, México. Pp. 11-28.

Estévez, A. (2018). "El dispositivo necropolítico de producción y administración de la migración forzada en la frontera Estados Unidos-México" [The necropolitical dispositif of production and administration of forced migration at the United StatesMexico Border]. Estudios Fronterizos, 19, e010. https://doi. org/10.21670/ref.1810010.

González Calleja, E. (2017). Asalto al poder. La violencia política organizada y las ciencias sociales. España: Editorial Siglo XXI. Guerrero Agripino, L. F. y De Santiago Álvarez, A. (2013). "El uso legítimo de la fuerza policial: breve acercamiento al contexto mexicano". Revista Ciencia Jurídica, Universidad de Guanajuato, núm. 03, año 1. Pp. 31-58.

Guevara Bermúdez, J. A. y Chávez Vargas, L. G. (2018). "La impunidad en el contexto de la desaparición forzada en México”. Economía. Revista en cultura de la legalidad, núm. 14, abrilseptiembre 2018. Pp. 162-174. https://doi.org/10.20318/eunomia.2018.4161 
Guzmán-Vera, M. G. (2018). La argumentación jurídica de las desapariciones forzadas en México. Trabajo de obtención de grado, Maestría en Derecho Constitucional y Argumentación Jurídica. Tlaquepaque, Jalisco: ITESO. Consultar en: https://rei.iteso.mx/ bitstream/handle/11117/5566/La\%20argumentaci\%C3\%B3n\%20 jur\% C3\%ADdica\%20de\%20las\%20desapariciones\%20forzadas $\% 20$ en $\% 20 \mathrm{M} \% \mathrm{C} 3 \%$ A9xico.pdf?sequence=2.

Human Rights Watch (2009). Impunidad uniformada, uso indebido de la justicia militar en México para investigar abusos cometidos durante operativos contra el narcotráfico y de seguridad pública. Consultar en https://www.hrw.org/es/report/2009/04/29/ impunidad-uniformada/uso-indebido-de-la-justicia-militar-enmexico-para-investigar.

López Portillo Vargas, E. (2011). Las fuerzas armadas en las calles. Revista Dfensor, Revista de Derechos Humanos, CDHDF, núm. 08, año IX. Pp. 06-08.

Mbembe, A. (2011). Necropolítica. España: Editorial Melusina.

Meyer, M. (2019). Propuesta de Guardia Nacional concretizaría la militarización de la seguridad pública en México. Publicado en WOLA, 10 de junio del 2019. Consultar en https://www.wola. org/es/analisis/guardia-nacional-mexico-abusos-militares/.

Meyer, M., Brewer, S. y Cepeda, C. (2010). Abuso y miedo en Ciudad Juárez: un análisis de violaciones a los derechos humanos cometidas por militares en México, Washington, D.C./México City, WOLA-Centro Prodh. Consultar en http://idpc.net/es/publications/2010/11/abuso-miedo-cuidad-juarez

Monárrez Fragoso, J. E. (2019). “Feminicidio sexual sistémico: impunidad histórica constante en Ciudad Juárez, víctimas y perpetradores". Estado \& comunes, revista de políticas y problemas públicos. Instituto de Altos Estudios Nacionales (IAEN). Quito-Ecuador, núm. 8, vol. 1. Pp. 85-110.

Muñoz Castellanos, J. (2017). “¿Qué es la seguridad pública para México? Gendarmería y proximidad social como estrategias policiales". Diké. Revista de Investigación en Derecho, Criminología y Consultoría. Benemérita Universidad Autónoma de 
Puebla, México. Año 11, Volumen 21 abril-septiembre del 2017. Pp. 145-167.

OEA (1994). Convención Interamericana sobre Desaparición Forzada de Personas. Consultar https://www.oas.org/juridico/spanish/tratados/a-60.html.

ONU (1992). Declaración sobre la protección de todas las personas contra las desapariciones forzadas. Consultar en http://www. ordenjuridico.gob.mx/TratInt/Derechos\%20Humanos/INST\%20 22.pdf

Orquíz, M. (2019). Relega Guardia Nacional plan anticrimen en Ciudad Juárez. La Verdad Juárez, Chihuaha, México. Consultado el 13 de enero del 2020 en https://laverdadjuarez.com/index.php/2019/09/08/relega-guardia-nacional-plan-anticrimenen-ciudad-juarez/.

Padilla Oñate, S. (2019). Los límites a la militarización de la seguridad pública en México. Revista Animal Político, nota editorial del 23 de octubre del 2019. Consultar en https://www.animalpolitico.com/el-blog-de-causa-en-comun/los-limites-a-la-militarizacion-de-la-seguridad-publica-en-mexico/

Parayre, S. (1999). "La desaparición forzada de personas como violación continuada de los derechos humanos y su incidencia en la determinación de la competencia ratione temporis de la Corte Interamericana de Derechos Humanos". Revista IIDH, Volumen 29. Pp. 25 a 67.

Quintana S., V. M. (2013). “Contexto y proceso de las desapariciones forzadas en el estado de Chihuahua. Un primer acercamiento". Chihuahua Hoy, Tomo XI, Universidad Autónoma de Ciudad Juárez, México. Pp. 525-548.

Reyna Ontiveros, P. (2019). Análisis de la Ley de Seguridad Interior en México. DÍkÊ. Revista de investigación en derecho, criminología y consultoría jurídica. Benemérita Universidad Autónoma de Puebla, México. Año 13, núm. 25, abril-septiembre de 2019. Pp. 39-68.

Salazar Gutiérrez, S. y Curiel García, M. M. (2012). Ciudad Abatida. Antropología de las fatalidades. México: Editorial UACJ. 
WOLA (2017). Justicia olvidada. La impunidad de las violaciones a derechos humanos cometidas por soldados en México. Consulta en https://www.wola.org/es/analisis/informe-de-wola-justicia-olvidada-la-impunidad-de-las-violaciones-derechoshumanos-cometidas-por-soldados-en-mexico/.

Woodrow Wilson International Center for Scholars (2009). Mexico-Merida Initative Report. Consultar en https://www.hsdl. org/?abstract\&did=33501. 